\title{
Malaysian youth perception on cyberbullying: the qualitative perspective
}

\begin{abstract}
Cyberbullying is not an emerging new problem and number of international scholars have placed their interest on the issue. In Malaysia, although the number of cyberbully studies are increasing, however, studies on cyberbullying in particular from the qualitative perspective is still lacking. This has geared the current study to prod youth perception on cyberbullying from the qualitative perspective. Their perceptions on cyberbullying were based on six main aspects, namely their comprehension of it, sources of their knowledge, examples that they know, the reasons for youth involvement in cyberbullying and their suggestions on how to prevent cyberbullies. This study involved a total of four FGDs with 27 participants among youth aged between 20-30 years old. A number of discussions are placed and hopefully this study can further enhance understanding on cyberbullying among youths in Malaysia.
\end{abstract}

Keyword: Cyberbully; Youth development; Internet usage 